\title{
USOS E SIGNIFICADOS DO DINHEIRO: UMA ANÁLISE DAS ESTRATÉGIAS DOS MEDIADORES PARA ATUALIZAÇÃO DE CIRCUITOS ECONÔMICOS
}

USES AND MEANINGS OF MONEY: AN ANALYSIS OF THE STRATEGIES OF THE MEDIATORS IN UPDATE OF ECONOMIC CIRCUITS USOS Y SIGNIFICADOS DEL DINERO: UN ANÁLISIS DE LAS ESTRATEGIAS DE MEDIADORES EN LA ACTUALIZACIÓN DE CIRCUITOS ECONÓMICOS

\section{RESUMO:}

Este estudo tem por objetivo levar à compreensão do leitor as estratégias adotadas pelos mediadores para oferecer suporte simbólico às transações monetárias, operadas a partir do acesso de agricultores familiares ao crédito. Para entender essa questão, foi realizado um estudo qualitativo com entrevistas e análise de discursos com base em um Sistema de Crédito Cooperativo, denominado Cresol SC/RS. 0 aporte teórico que orientou a análise das informações articulou os conceitos de "marcos interpretativos", de McAdam, McCarthy e Zald (1999), com a noção de "circuitos econômicos" de Zelizer (2005). A conclusão é a de que os mediadores atuam permanentemente na construção de significados para utilização do dinheiro. Suas estratégias propõem um alinhamento entre as dimensões da racionalidade instrumental e 0 sistema de valores, articulando as expectativas individuais dos agricultores com as estratégias organizacionais do circuito econômico.

Palavras-chave: Marcos interpretativos, Circuitos econômicos, Políticas públicas, Cultura, Cooperativas de crédito.

Jandir Pauli - jandir@imed.edu.br

Doutor em Sociologia pela UFRGS.

Professor Titular I na Faculdade Meridional (IMED).

Marcelino Pies - marcelino@imed.edu.br

Professor de Ciência Política na Faculdade Meridional IMED

Artigo submetido no dia 12-06-2013 e aprovado em 08-12-2014 
Jandir Pauli - Marcelino Pies

ABSTRACT:

This study aims to understand the strategies adopted by the mediators to offer symbolic support for monetary transactions, operated from the access to credit for family farmers. To understand this question, a qualitative study was conducted in a Cooperative Credit System, called CRESOL SC / SR. The theoretical framework that guided the analysis of the information articulated the concepts of "interpretive frameworks", by McAdam, McCarthy and Zald (1999) with the notion of "economic circuits" by Zelizer (2005). The conclusion is that mediators work permanently in the construction of meanings for the use of money. Their strategies propose an alignment between the dimensions of instrumental rationality to the system of values, linking the individual expectations of the farmers with the organizational strategies of the economic circuit.

Keywords: Interpretive frameworks, Economic circuits, Public policy, Culture, Cooperatives of credit.

\section{RESUMEN:}

Este estudio tiene como objetivo comprender las estrategias adoptadas por los mediadores para ofrecer apoyo simbólico para las transacciones monetarias, operadas desde el acceso al crédito para los agricultores familiares. Para comprender esta cuestión, un estudio cualitativo se llevó a cabo en un Sistema de Crédito Cooperativo llamado CRESOL SC I SR. El marco teórico que guió el análisis de la información articula los conceptos de "marcos interpretativos", de McAdam, McCarthy y Zald (1999) con la noción de "circuitos económicos" por Zelizer (2005). La conclusión es que los mediadores trabajan de forma permanente en la construcción de significados para el uso del dinero. Sus estrategias proponen una alineación entre las dimensiones de la racionalidad instrumental para el sistema de valores, que une las expectativas individuales de los agricultores con las estrategias de la organización del circuito económico.

Palabras clave: Marcos interpretativos, Circuitos Económicos, Política Pública, Cultura, cooperativas de crédito.

\section{Introdução}

O tema da influência do crédito na reorganização da vida social vem recebendo destaque nas ciências sociais por problematizar o alcance da compreensão do mercado como sistema de regulação homogeneizante e a interferência de elementos extraeconômicos na mobilização da ação econômica. E quando o crédito provém de políticas públicas e é mediado por organizações sociais, a interferência dos aspectos culturais e políticos torna-se ainda mais visível na medida em que se estabelece uma relação de médio e longo prazo - expressa no compromisso da dívida - entre o tomador e a organização intermediadora. A partir desse contexto, surgem algumas interrogações: "Qual o significado que os indivíduos conferem ao dinheiro obtido por meio do acesso ao crédito? E no caso do acesso intermediado por instituições financeiras de caráter cooperativo, quais as características dos laços so- ciais gerados nessa relação?"

Para operar o problema de pesquisa deste estudo, foram utilizados os conceitos de Circuitos econômicos e Mediadores. Para analisar as transferências econômicas, a socióloga estadunidense Viviana Zelizer propôs uma ferramenta analítica denominada Circuito econômico, entendido como uma configuração social e econômica que permite a circulação de acordos, práticas, informações, instrumentos de troca e símbolos partilhados nesse ambiente. Cada um desses circuitos é caracterizado por: 1) limites mais ou menos precisos e algum controle sobre suas fronteiras; 2) laços pessoais significativos entre seus membros; 3 ) transações econômicas próprias e instrumentos de troca com base na reciprocidade (Zelizer, 2005, p. 96).

A noção de mediadores utilizada neste estudo remete às elaborações de Dough McA- 
USOS E SIGNIFICADOS DO DINHEIRO: UMA ANÁLISE DAS ESTRATÉGIAS DOS MEDIADORES PARA ATUALIZAÇÃO DE CIRCUITOS ECONÔMICOS

dam, John McCarthy e David Zald (1999), que, recorrendo às elaborações de David Snow e Robert Benford (1992), propõem os conceitos de frames (quadros de referência) como articulação entre a ideologia dos movimentos e a dimensão cognitiva de seus integrantes. Os mediadores atuam no alinhamento (articulação) entre os valores, sentimentos, visões de mundo individuais e a pretensão de legitimidade da política pública. Em outros termos, os mediadores seriam responsáveis pela elaboração, articulação e proposição de referenciais que buscam definir, justificar e legitimar as práticas sociais nos contextos específicos.

Para fortalecer a análise do problema de pesquisa, foi realizado um estudo empírico sobre um Sistema de Cooperativas de Crédito com Interação Solidária, denominado Cresol Central SC/RS. Com sede na cidade de Chapecó/SC, o sistema articula, em uma central, um conjunto de cooperativas de crédito rural dos Estados de Santa Catarina (SC) e do Rio Grande do Sul (RS). A partir dos dois conceitos operacionais, foi estruturada a problemática deste estudo: como elementos culturais e valorativos são misturados às transações econômicas e quais são as estratégias adotadas pelos mediadores para oferecer suporte simbólico às práticas econômicas no circuito Cresol SC/RS? Em outras palavras, procurou-se compreender como a ação dos mediadores contribui para que o sistema de valores forneça suporte para as relações econômicas no circuito e como elas são afetadas pela lógica financeira.

Para compreender as estratégias dos mediadores para significação do dinheiro no circuito Cresol SC/RS, foram utilizados métodos de análise qualitativa a partir da organização de um corpus de pesquisa (Bauer e Gaskell, 2002, p. 44-5), constituído por 25 entrevistas semiestruturadas e por informações coletadas em documentos e publicações institucionais. A amostra das entrevistas foi realizada por conveniência e realizada nas cooperativas, nos encontros de formação e nas propriedades de agricultores, sendo divididas em dois grupos: o primeiro, composto por 17 mediadores, que são os diretores (abreviados pela sigla DIR), assessores e técnicos (abreviados pela sigla TEC), e o segundo, por oito agricultores associados em diferentes cooperativas (abreviados pela sigla AGR).

Essa estratégia metodológica permitiu observar a aproximação entre as compreensões individuais e as expectativas organizacionais, procurando assimilar como as práticas são estruturadas. $O$ tratamento das informações foi feito utilizando a análise de conteúdo, que classificou os dados coletados a partir das entrevistas e da observação com enfoque qualitativo, analisando a presença ou ausência de determinados temas.

\section{Apresentação do objeto empírico: Cre- sol e Agricultura familiar}

O Sistema Cresol de cooperativas de crédito surgiu em 1995 a partir de uma coalizão entre organizações do meio rural dos Estados do Paraná (PR), Santa Catarina (SC) e Rio Grande do Sul (RS), especialmente entre Organizações Não Governamentais (ONGs), movimentos sociais, sindicatos de trabalhadores, partidos políticos, com amplo apoio da ala progressista da igreja católica (inspirada nas experiências das chamadas Comunidades Eclesiais de Base - CEBs). 
Naquele contexto, a Central cumpria basicamente a função de articulação política e suporte técnico e contábil para as operações financeiras das cooperativas do Sistema, a chamada Base de Serviços (Baser). A primeira Cooperativa Singular Cresol surgiu no Sudoeste do PR, no município de Dois Vizinhos. Em 2000, já atendendo à normativa do Banco Central, foi criada a Cresol-Baser (Base de Serviços) e, em 2004, ocorreu a criação da Cresol Central SC/RS que passou a articular as cooperativas dos Estados do Sul, especificamente do RS e $\mathrm{SC}$, ficando a Cresol-Baser com a responsabilidade de articular a maioria das cooperativas paranaenses. Em termos práticos, cada Central passou a operar de maneira autônoma na elaboração de sua estratégia, mas o desmembramento foi motivado basicamente para cumprir uma exigência normativa do Banco Central.

Nas informações institucionais, disponíveis no site institucional, a Cresol Central SC/RS se define como "um sistema de cooperativas de crédito rural com interação solidária, que surgiu para oferecer, além dos serviços financeiros, crédito, desenvolvimento e inclusão social aos agricultores familiares". Sua missão é "fortalecer e estimular a interação solidária entre cooperativas e agricultores familiares através do crédito e da apropriação de conhecimento, visando ao desenvolvimento local e sustentável.' A organização é norteada pelos seguintes valores: democracia; articulação com movimentos populares; gestão pelos agricultores familiares; transparência; solidariedade e cooperação; descentralização, e honestidade. Ainda, como diferenciais, são apresentados o controle social como garantia de transparência administrativa e a opção em financiar projetos na área da agroecologia e bioconstruções, sempre com assessoramento técnico das cooperativas associadas.

Em dez anos, segundo os números do balanço social de 2013, a Cresol Central SC/ RS passou a contar com 100 mil associados, distribuídos em 63 Cooperativas Singulares e oito Bases de Serviços, e mais de cem Unidades de Atendimento. Seu raio de atuação se estende a mais de 150 municípios, prioritariamente nos Estados do RS e SC.

Do ponto de vista financeiro, no mesmo período, o sistema com mais de 150 milhões em patrimônio, 300 milhões em Pronaf (Programa Nacional de Desenvolvimento da Agricultura Familiar) Custeio (35 mil contratos), 164 milhões em Pronaf Investimento (6,7 mil contratos), 450 milhões em empréstimos/ crédito com recursos próprios ( 75 mil contratos), mais de 2 mil casas construídas com recursos dos programas de Habitação Social - PSH e PMCMV (Ministério das Cidades), 1.200 bilhões em ativos e com um resultado financeiro de 12 milhões de reais. Na série histórica, todas as informações fornecidas pelo Sistema mostram uma evolução constante e intensa, crescendo mais de $200 \%$ ao ano. Percentuais que seguem a mesma tendência nos gráficos de ampliação da área de atuação, captação e liberação de crédito (projetos).

A origem e a identidade da Cresol estão ligadas a dois temas: de um lado, a ação contestatória por meio da contestação política do modelo social e econômico e, de outro, o sentido propositivo, expresso na implantação de instrumentos que buscam atender às necessidades econômicas, sociais e culturais dos agricultores. $\mathrm{O}$ crédito em dinheiro é $\mathrm{O}$ 
USOS E SIGNIFICADOS DO DINHEIRO: UMA ANÁLISE DAS ESTRATÉGIAS DOS MEDIADORES PARA ATUALIZAÇÃO DE CIRCUITOS ECONÔMICOS

ponto de articulação entre essas duas dimensões: representa o resultado de um processo histórico e de positivação de pautas dos movimentos sociais que atuam no meio rural ao mesmo tempo em que cria os contornos da organização e coloca em relação, por um conjunto de dispositivos organizacionais, os atores econômicos que atuam no Sistema. Há, portanto, uma expectativa de alinhamento entre o conteúdo que define a função do crédito para a agricultura familiar e o significado das operações financeiras no dia a dia dos agricultores.

Desde o seu surgimento, uma das principais estratégias de operação do Pronaf é a transferência de recursos para as Cooperativas de Crédito (via bancos públicos), tornando-as agentes intermediários entre a política pública e os beneficiários, ao mesmo tempo em que estão submetidos à fiscalização do Banco Central. Essas cooperativas teriam maior capacidade de garantia de que os recursos tenham um destino correto e promovam a inclusão socioeconômica dos agricultores por sua proximidade e identificação com o público-alvo (Abramovay e Bittencourt, 2003; Abramovay, 2004).

O Sistema Cresol se desenvolveu a partir do surgimento do Pronaf. Leva-se em conta que a criação desse programa contrasta com o discurso hegemônico na agricultura brasileira, que historicamente se beneficiou do acesso ao crédito, advogando a sua importância na balança comercial e na colocação do país no mercado internacional como produtor de commodities. Esse processo da agricultura brasileira é amplamente analisado pela literatura e conhecido como "Revolução Verde." Por isso, o Programa foi percebido pelos atores da agricultura familiar como importante ferramenta de resistência frente ao avanço do modelo de agricultura da "Revolução Verde".

É interessante observar que o surgimento do Cresol em 1995, o lançamento do Pronaf em 1996 e a construção da expressão "Agricultura Familiar" estão umbilicalmente relacionados. Segundo Schneider (2003), essa expressão surgiu no Brasil a partir de dois eventos significativos: 1) como expressão-síntese das reivindicações de diferentes movimentos sociais rurais, especialmente pela ação da Confederação Nacional dos Trabalhadores da Agricultura Familiar (Contag); 2) pela legitimação atribuída pelo Estado quanto à utilização dessa expressão para definição do Pronaf. Aliás, a expressão "Agricultor Familiar" aparece textualmente no Art. 30 da Lei do Pronaf (Lei n. 11.326, de 24/07/2006) para conceituar esse agente econômico, sem referir-se a conceitos amplamente conhecidos na literatura como "pequeno produtor", "colono" ou "campesino".

Para os fins deste estudo, a identidade cultural do agricultor familiar é definida em diferenciação ao campesinato tradicional, uma vez que este historicamente utilizou a propriedade para a agricultura de subsistência. Adota-se aqui a definição dada pelo contexto político do surgimento da expressão no Brasil. que enfatiza sua relação com o mercado por meio do acesso ao crédito, da agregação de valor e da inserção na dinâmica do mercado pela aquisição de insumos e comercialização. Nas palavras de Abramovay (1992, p. 22) "[...] uma agricultura familiar altamente integrada ao mercado, capaz de incorporar os principais avanços técnicos e de responder às políticas governamentais não pode ser nem de longe caracterizada como 
camponesa.' Em outros termos, trata-se de uma definição fabricada pela relação entre movimentos sociais com o Estado.

\section{Circuitos econômicos e marcos inter- pretativos}

Este estudo incorpora o conceito de Zelizer de que a utilização do dinheiro é organizada em circuitos econômicos (2002; 2005, 2010), que permitem sua significação. Essa perspectiva a afasta do mainstream da Sociologia econômica, uma vez que, para a socióloga, existem "múltiplos dinheiros", que são significados nesses ambientes pela combinação entre lógica econômica, intimidade e sistema de valores, que estão na base da identificação do circuito.

A partir dessa noção, este estudo explorou as transformações nas relações sociais ocorridas na Agricultura Familiar a partir da intensificação da circulação do dinheiro. A noção de Circuito será utilizada como sinônimo de Sistema, procurando demonstrar que a ação dos mediadores na formação da identidade da Cresol está orientada para a criação de uma complexa rede de significados que mesclam elementos de ordem: 1) política (simetria nas relações de poder, proximidade com a realidade do agricultor, linguagem acessível e orientação do crédito); 2) cultural (importância da família, cooperação e ajuda mútua); 3) econômica (juros mais baixos, acompanhamento técnico, financiamento desburocratizado da produção e do consumo); 4) afetiva (confiança, reciprocidade, amizade e cuidado/zelo). Além disso, na organização desse circuito, o dinheiro emerge como principal meio de articulação entre a dimensão racional/instrumental e um sistema de valores, que identifica e demar- ca as fronteiras das transações econômicas com as transações não econômicas.

As características dos circuitos econômicos podem ser resumidas em cinco pontos: 1) comportam diferentes relações sociais entre os indivíduos específicos; 2) permitem compartilhar as atividades econômicas realizadas por essas relações sociais, isto é, "os laços entre os participantes têm o significado compartilhado"; 3) criam sistemas de contabilidade comuns para avaliar o intercâmbio econômico, por exemplo, formas particulares de dinheiro; 4) compartilham os significados que as pessoas atribuem a suas atividades econômicas, isto é, "um conjunto distinto de transferência de bens, serviços ou reivindicações dentro de seus laços interpessoais"; 5) estabelecem uma fronteira clara entre os membros do circuito não membros, com algum controle sobre as transações que atravessam a fronteira (Zelizer, 2010, p. 315). Dessa forma os circuitos possuem limites mais ou menos precisos e algum tipo de controle sobre as transações que acontecem além de suas fronteiras. Essas transações estão apoiadas sobre laços interpessoais que partilham significados e cada circuito econômico é um tipo de agenciamento entre intimidade e economia de cada espaço da vida social.

Leva-se em conta que esse circuito busca caracterizar um mercado específico, localizado e recortado em uma realidade social particular. Do ponto de vista estritamente econômico, o Sistema Cresol SC/RS parece somente cumprir um papel de inclusão dos agricultores familiares no modelo de mercado, que, dito de outra forma, representa um avanço do mercado sobre um espaço antes inexplorado. No entanto, essa ideia não se sustenta 
USOS E SIGNIFICADOS DO DINHEIRO: UMA ANÁLISE DAS ESTRATÉGIAS DOS MEDIADORES PARA ATUALIZAÇÃO DE CIRCUITOS ECONÔMICOS

porque o que há de específico nesse circuito não se resume à introdução do cálculo e do dinheiro ou mesmo à passagem do tradicionalismo econômico para uma visão empresarial da unidade doméstica, abrindo-a para o mercado, mas à capacidade de utilização do dinheiro para transportar significados e ideologias. Em outros termos, ao passo que serve de suporte para as relações sociais, 0 dinheiro permite a caracterização do circuito, porque ele transporta valores econômicos e culturais. Ele carrega os significados construídos pelas relações sociais no circuito.

Com esse plano de fundo, este estudo detém-se na compreensão do processo de significação cultural do dinheiro em um circuito específico. $\mathrm{O}$ objetivo é demonstrar que a produção de símbolos e a significação cultural constituem-se em um circuito econômico com fronteiras mais ou menos definidas e identificadas por quadros de referência (frames), que funcionam como "processos de encaixe" entre a expectativa individual dos atores e o fortalecimento da organização por meio da mobilização coletiva. Isso permitirá desenvolver a hipótese de que a modelagem e atualização dos quadros de referência desses circuitos sejam elaboradas pelos chamados "mediadores", que cumprem a função de alinhar o conteúdo institucional com as práticas de utilização do dinheiro no circuito.

Além da noção de circuito, este estudo incorpora o conceito de "marcos interpretativos". Nesse ínterim, conforme já apresentado na primeira parte deste estudo, é possível caracterizar o surgimento do circuito Cresol SC/RS como resultado de "processos coletivos de interpretação, atribuição e constru- ção social, que mediam a oportunidade e a ação" (McAdam, McCarthy e Zald, 1999, p. 23). Nesse ambiente, a Agricultura Familiar é qualificada, do ponto de vista simbólico, como produtora de alimentos, e a unidade familiar rural como lugar da produção para o autoconsumo, sendo que o excedente pode ser comercializado no "mercado" e em "mercados paralelos" (alternativos), construídos pela parceria entre os atores da agricultura familiar.

Conforme Zald (1999, p. 370), a relação entre movimentos, a criação de "marcos interpretativos" e a sociedade em geral são mutuamente afetadas por seis pontos: 1) construção cultural de repertórios de argumentos e os marcos nos quais se enquadram; 2) contradições culturais e sucessos históricos que permitem levar adiante o processo de "encaixe"; 3) criação de "marcos interpretativos" como atividade estratégica dos movimentos; 4) processos competitivos que resultam na escolha de um marco interpretativo dominante; 5) difusão dos marcos por meios de comunicação, especialmente de massa; 6 ) confronto entre oportunidades políticas e mobilização para dar forma ao resultado das lutas entre os diferentes marcos.

Assim, este estudo reconhece que o Pronaf cria um ambiente de oportunidades políticas, e a existência do Sistema Cresol somará esforços para fortalecer um modelo de agricultura, que catalise um conjunto de atores na defesa desse grupo social conhecido como Agricultor Familiar, construindo uma ideologia elaborada a partir da visão de mundo compartilhada em torno da necessidade de mudanças estruturais em relação ao modelo de agricultura da "Revolução Verde". 
Jandir Pauli - Marcelino Pies

\section{Estratégias dos mediadores para sig- nificação do dinheiro no circuito Cresol SC/RS}

A partir de agora será demonstrado como os mediadores desenvolvem suas estratégias no circuito Cresol SC/RS. A caracterização do sentido e a utilização do dinheiro definem o Circuito como espaço de coexistência contínua entre laços pessoais e atividades econômicas, por isso interessa compreender os tipos de significado que esses ambientes organizacionais conferem às transações monetárias e como o crédito, ao mesmo tempo em que satisfaz necessidades de ordem prática, racional e utilitarista, sofre as influências do sistema de valores e dos sentimentos e significados. É nesse contexto que surgem os mediadores com a tarefa de elaborar a atribuição de sentido às transações econômicas e a negociação desse sentido junto aos agricultores. Por isso interessa saber como as práticas da significação, que são manifestas na abertura das transações monetárias, interagem com a intimidade e como o poder e a negociação influenciam na definição da agenda e no desenvolvimento de práticas monetárias concretas.

Assim, recupera-se a questão central deste estudo que trata da interpretação simbólica e ideológica que os mediadores articulam e operam no processo de atribuição de sentido e mobilização da ação econômica, bem como a forma como suas estratégias são negociadas e demarcam os limites e identidades de circuitos econômicos. Em outros termos, procura-se compreender as estratégias engendradas pelos agentes econômicos na interpretação e reelaboração de quadros de referência (frames), que incorporam elementos de ordem simbólica e valorativa à racionalidade econômica, e como os "marcos interpretativos" do circuito são atualizados constantemente.

\section{Análise dos dados: atualizações dos marcos interpretativos do circuito Cresol SC/RS}

Os dados encontrados na realidade empírica permitem estabelecer que, até o estágio atual, o Sistema Cresol realizou três grandes atualizações, mencionadas a seguir.

Primeira elaboração (entre os anos de 1994 e 1997, aproximadamente): Criação do Sistema Cresol. Sob o conceito de pequenos produtores, a organização emergente enfatiza o caráter fechado da unidade doméstica, associado à circulação restrita de dinheiro. Bastante articulados aos repertórios de mobilização das ONGs, Movimentos Sociais e Sindicatos de Trabalhadores Rurais (STRs), os elementos de referência simbólica desse contexto estimulam a mobilização coletiva, o engajamento e a contestação do modelo de agricultura do sistema financeiro de crédito e, do ponto de vista mais amplo, do desenvolvimento social. É importante destacar que a Cresol surgiu de um consenso entre diversas organizações do meio rural que antes operavam o chamado "Crédito Rotativo", formado pelos fundos constituídos por doações de instituições ligadas, especialmente, à Igreja Católica, e que condicionava os agricultores a estar inseridos em associações comunitárias para ter acesso aos recursos financeiros.

Em sentido mais específico, surge a ideia de cooperativa como ferramenta para organizar o dinheiro. Essa organização ganha forma a partir da cooperativa, pois esse formato ins- 
USOS E SIGNIFICADOS DO DINHEIRO: UMA ANÁLISE DAS ESTRATÉGIAS DOS MEDIADORES PARA ATUALIZAÇÃO DE CIRCUITOS ECONÔMICOS

titucional permite, especialmente, a individualização das relações de crédito (dívida) e a ampliação da circulação de dinheiro no circuito. $O$ crédito abriu a gestão da unidade doméstica/familiar e os mediadores passaram a fazer parte do dia a dia das famílias. Estar na "propriedade" e conhecer bem os agricultores tornam-se exigência básica para o bom desempenho das relações de crédito.

Nessa primeira atualização, a estratégia dos mediadores articulou, basicamente, dois temas: a individualização da relação (espe- cialmente pela emergência dos contratos por CPF), o que permitiu o acesso às informações financeiras de cada tomador, e o cálculo de sua capacidade de endividamento. Antes a relação era com o grupo, e toda análise de capacidade de pagamento era feita a partir das capacidades do grupo (coesão, estrutura interna das relações sociais e disposição dos integrantes para cooperação e ajuda mútua). Essa inovação condicionou os agricultores a expor seus projetos privados, abriu sua propriedade e exigiu um sistema de contabilidade (gestão) dos recursos contraídos mediante empréstimo.

Quadro síntese dos significados e novas práticas adotadas pelo circuito

\begin{tabular}{|l|l|}
\hline \multicolumn{1}{|c|}{ Antes do Fundo de Crédito Rotativo } & Constituição do circuito - Primeira elaboração \\
\hline Acesso ao crédito por meio do grupo & Acesso individualizado \\
\hline $\begin{array}{l}\text { Definição sobre a aplicação dos recursos } \\
\text { feita pelo grupo }\end{array}$ & $\begin{array}{l}\text { Liberdade de escolha da finalidade de utilização } \\
\text { do dinheiro }\end{array}$ \\
\hline Sem compromisso com instituição financeira & $\begin{array}{l}\text { Contrato com instituição reconhecida pelo } \\
\text { sistema financeiro nacional }\end{array}$ \\
\hline Participação na associação & Participação na gestão da cooperativa \\
\hline $\begin{array}{l}\text { Simbologia partilhada: pequenos agricultores } \\
\text { isolados são sinônimos de dispersão e } \\
\text { vulnerabilidade social }\end{array}$ & $\begin{array}{l}\text { Pequenos agricultores organizados em } \\
\text { cooperativas são fortes e com capacidade } \\
\text { competitiva }\end{array}$ \\
\hline $\begin{array}{l}\text { O pouco dinheiro dos agricultores está } \\
\text { disperso no sistema financeiro oficial e } \\
\text { privado }\end{array}$ & $\begin{array}{l}\text { Do ponto de vista financeiro: Cresol procura } \\
\text { organizar o dinheiro }\end{array}$ \\
\hline $\begin{array}{l}\text { Organizações de referência: lgrejas, ONGs, } \\
\text { STRs. Temas: comunitarismo e ecologia }\end{array}$ & $\begin{array}{l}\text { Organizações de referência: sistema financeiro, } \\
\text { outros circuitos de crédito cooperativo. Temas: } \\
\text { cooperativismo e desenvolvimento }\end{array}$ \\
\hline
\end{tabular}

Fonte: Sistematização feita pelo autor. 
Segunda elaboração (entre 1998 e 2003, aproximadamente): diferenciação do circuito em relação aos sistemas de crédito cooperativo tradicionais. Com a expansão do Pronaf, outras cooperativas de crédito passaram a atuar no meio rural. Nesse ponto, os mediadores desenvolveram estratégias para fortalecer uma relação de reciprocidade e confiança com os associados em torno do conceito de Agricultura Familiar e cooperativismo de crédito. Essa elaboração é fundamental, porque associou elementos de ordem pessoal e valorativa dos beneficiários da política pública, ao passo que intensificou a utilização do dinheiro. $O$ custeio da produção passou a ser o ponto de encontro, articulando elementos da racionalidade instrumental dos associados com a aproximação do sistema financeiro (aptidão das cooperativas para receber recursos da política pública) e de setores do Governo Federal, especialmente do Ministério do Desenvolvimento Agrário. A aproximação com o sistema oficial de crédito instaurou uma agenda de afastamento em relação aos movimentos sociais, ONGs e STRs. As cooperativas passaram a ter mais contato (e um contato direto) com os agricultores que intensificaram a circulação de dinheiro apostando em relações de crédito mais duradouras, mesmo que permeadas pela relação de dívida.

Na segunda elaboração/atualização, os mediadores empenharam-se na diferenciação do circuito Cresol em relação aos demais circuitos. A estratégia foi a aproximação com a política pública do Pronaf pela articulação entre o ideal cooperativista e o conceito de Agricultura Familiar. Nesse sentido, desenvolveu-se a ideia de que o engajamento na causa social da cooperativa passa a gerar lucros individuais como inclusão social por meio da política pública e baixo custo do dinheiro (juros). No entanto, aproximar-se da política pública significa incorporar as regras do sistema financeiro nacional. Os mediadores precisam diferenciar as cooperativas dos Bancos e, para isso, o tema da participação na gestão da cooperativa passa a ser estratégico. A construção da confiança transmite a ideia de "esta casa é sua", slogan estampado nas fachadas das cooperativas constituídas ainda na formação do circuito.

Nesse processo, a relação do circuito Cresol com o SFN e o surgimento de outros sistemas de crédito ameaçaram, pela primeira vez, a identidade do Circuito. Os mediadores passaram então a atuar no fortalecimento interno, e as estratégias tornaram-se de estruturação organizativa das cooperativas para adoção do princípio da descentralização, desmembrando cooperativas maiores em pequenas e médias, na expectativa da maior aproximação com os agricultores. Esse também foi o momento da institucionalização de programas de investimento (além do custeio da produção de cereais) por meio das parcerias com o Banco Nacional de Desenvolvimento Econômico e Social (BNDS) e o Banco Regional de Desenvolvimento Econômico (BRDE). A elaboração de projetos e sua viabilidade serão praticamente coordenadas pelas cooperativas. Surge o Programa de Crédito Orientado para expansão do domínio das cooperativas sobre a atividade financeira das famílias. A racionalidade econômica passou a ser estimulada, sempre acompanhada pela vigilância do desenvolvimento institucional da cooperativa e pela busca de maior comprometimento por parte dos associados com a gestão da cooperativa. 
USOS E SIGNIFICADOS DO DINHEIRO: UMA ANÁLISE DAS ESTRATÉGIAS DOS MEDIADORES PARA ATUALIZAÇÃO DE CIRCUITOS ECONÔMICOS

Quadro síntese dos significados e novas práticas adotadas pelo circuito

\begin{tabular}{|l|l}
\hline \multicolumn{1}{|c|}{ Elaboração anterior (primeira) } & \multicolumn{1}{c}{ Segunda elaboração } \\
\hline Pequeno agricultor & Agricultor Familiar \\
\hline Crédito de Custeio da safra & Crédito produtivo + investimentos \\
\hline $\begin{array}{l}\text { Recursos provenientes do Fundo de Capital } \\
\text { de Risco (FCR) e captação de recursos } \\
\text { próprios dos agricultores }\end{array}$ & $\begin{array}{l}\text { Recursos provenientes do Pronaf, do BNDS e do } \\
\text { BRDE }\end{array}$ \\
\hline $\begin{array}{l}\text { Mobilização social como forma de pressão } \\
\text { para acesso aos recursos }\end{array}$ & $\begin{array}{l}\text { Utilização das vias institucionais } \\
\text { (governamentais) como forma de pressão política }\end{array}$ \\
\hline $\begin{array}{l}\text { Símbolo: organização dos pequenos } \\
\text { agricultores para conseguir benefícios } \\
\text { coletivamente }\end{array}$ & $\begin{array}{l}\text { Símbolo: autoestima do Agricultor Familiar como } \\
\text { "produtor de alimentos para a nação" }\end{array}$ \\
\hline $\begin{array}{l}\text { Propriedade rural com caráter fechado e } \\
\text { certa restrição ao uso do dinheiro } \\
\text { Campesinato baseado no autoconsumo }\end{array}$ & $\begin{array}{l}\text { Caráter aberto da unidade doméstica. Relação } \\
\text { com o mercado via produção de alimentos } \\
\text { (comercialização) }\end{array}$ \\
\hline $\begin{array}{l}\text { Cooperação com base na ajuda mútua e na } \\
\text { rede de vizinhança }\end{array}$ & Aval solidário e solidariedade de contrato \\
\hline
\end{tabular}

Fonte: Sistematização feita pelo autor.

Terceira elaboração (após 2004 até os dias atuais): introdução do conceito de família e utilização do dinheiro para o "bem viver". Essa elaboração, além de coincidir com o surgimento da Cresol Central SC/RS, está em fase de consolidação. Expresso pelos conceitos de "construção da moradia" e "crédito para o bem-estar", o Circuito atualiza símbolos que aproximam elementos de ordem cultural com a racionalidade instrumental (cálculo). O tema da qualidade de vida entra em foco, e o acesso aos bens de consumo passa a ser sinônimo de inclusão social. O lançamento da política pública de construção e a reforma de moradias, além da ampliação da oferta de produtos e serviços como cartões de crédito, seguros e demais serviços financeiros, cristalizam o afastamento em relação aos movimentos sociais, STRs e ONGs e consolidam a aproximação com o sistema financeiro. Do ponto de vista da estratégia organizacional, o circuito tenta corrigir fluxos de dinheiro, procurando manter os recursos dos associados no Sistema.

Essa fase de atualização do circuito Cresol passou a ser caracterizada pela adoção da ideia de "família" no sentido amplo do termo e pela interferência nos hábitos de consumo da unidade doméstica. Surgem os produtos e serviços de uma instituição financeira completa, que, do ponto de vista econômi$\mathrm{co}$, procurou fechar o circuito, evitando que o dinheiro que circula nele evada as divisas. Assim, as cooperativas de crédito do Sistema Cresol SC/RS passam a disponibilizar recursos para aquisição de automóveis, ele- 
trodomésticos, moradia e reforma da casa, cartões de crédito, seguros (vida, produção, conservação de bens) e investimentos em aplicações financeiras diversas.

Nos discursos institucionais desse contexto, surge a "Cresol, que realiza sonhos." A muIher e as crianças emergem como sujeitos de cidadania em um modelo de família a ser resgatado e preservado. Nos materiais informativos e de divulgação, são destacadas imagens de famílias associadas a depoimentos confirmatórios. Discursos também percebidos nas entrevistas com os diretores:

Quais são os valores da Cresol? Os principais valores do sistema Cresol eu pra mim é o quanto ela conseguiu até hoje realizar de sonhos das famílias. Às vezes muito dessas pessoas trabalham com a Cresol e trabalham com outras instituições elas não tem basicamente na Cresol uma conta, mas a Cresol representa muito pra essas famílias. Se não tivesse o sistema Cresol eu não tenho dúvida que hoje o mercado teria excluído muito mais gente, as taxas de juros seriam muito mais exploradas, eu vejo que isso significa resultado, dinheiro do bolso das pessoas que trabaIham com o sistema Cresol; o custo é muito baixo (DIR1).

Além disso, com o crescimento acelerado do Sistema (em número de associados e ativos financeiros), a despersonalização das relações passa a ser considerada. Para isso, três práticas são adotadas: investimento em comunicação interna, inovações institucionais que otimizem a busca de informações sobre os candidatos ao crédito e intensificação da estratégia de aproximação com os agricultores. É nesse contexto que surge o slogan: "Cresol, mais que uma cooperativa de crédito, uma grande família".

Quadro síntese dos significados e novas práticas adotadas pelo circuito

\begin{tabular}{|l|l|}
\hline \multicolumn{1}{|c|}{ Segunda elaboração (anterior) } & \multicolumn{1}{c|}{ Terceira elaboração (atual) } \\
\hline Dinheiro para custeio e investimento & $\begin{array}{l}\text { Dinheiro para custeio, investimento e consumo } \\
\text { (bem-estar) }\end{array}$ \\
\hline $\begin{array}{l}\text { Movimentos sociais e mobilização para acesso ao } \\
\text { sistema financeiro de crédito }\end{array}$ & $\begin{array}{l}\text { Mediadores se fortalecem com interferência } \\
\text { política negociando as pautas para os } \\
\text { agricultores }\end{array}$ \\
\hline Agricultor Familiar que produz alimentos & Família, união e qualidade de vida \\
\hline $\begin{array}{l}\text { Família como unidade produtora com destaque } \\
\text { para utilização da mão de obra, especialmente } \\
\text { masculina }\end{array}$ & $\begin{array}{l}\text { Participação maior das mulheres e filhos } \\
\text { maiores (proteção dos filhos - seguro de vida) }\end{array}$ \\
\hline Dinheiro para produzir e capitalizar & $\begin{array}{l}\text { Dinheiro para produzir, capitalizar e para bem- } \\
\text { estar/consumo }\end{array}$ \\
\hline Seguro para proteção dos investimentos & $\begin{array}{l}\text { Dinheiro para proteção do estilo de vida da } \\
\text { familia }\end{array}$ \\
\hline
\end{tabular}

Fonte: Sistematização feita pelo autor. 
USOS E SIGNIFICADOS DO DINHEIRO: UMA ANÁLISE DAS ESTRATÉGIAS DOS MEDIADORES PARA ATUALIZAÇÃO DE CIRCUITOS ECONÔMICOS

Os dados coletados nas entrevistas ajudam a interpretar o trabalho dos mediadores na significação do dinheiro durante as atualizações do circuito. Perguntado sobre como o dinheiro afeta o Sistema, um diretor responde: "O dinheiro vai te fazendo mudar de pensamento mudar a organização. Tu vai percebendo que a organização precisa sobreviver no mercado e, para isso, precisa mudar os pensamentos, os valores, as crenças etc." (DIR5). A fala de outro diretor aponta para a mesma direção: "O dinheiro pode alterar as relações se você não trabalhar a lógica de para que ele serve, para que que ele entra na propriedade? Porque você recebe a lógica individualista de fora, que não é uma coisa construída ali na família" (DIR7). A resposta de um técnico confirma as opiniões anteriores: "Infelizmente está virando numa questão mais financeira. Conforme a cabeça pensante ele pode te reascender na vida, e conforme a cabeça pensante ele pode te matar. É uma arma! É uma arma perigosa"(TEC2).

Como já demonstrado, os mediadores atuam na proposição de símbolos e quadros de referência (frames) para articular a manutenção dos laços sociais com os novos elementos técnico-instrumentais, específicos da relação com o mercado. O "crédito assistido" passa a ser uma importante ferramenta no contexto do aumento da circulação de dinheiro, da abertura da unidade doméstica e da preservação dos laços sociais.

Hoje a maioria é assim: o pessoal vem para buscar um recurso, e a gente sempre procura conversar com ele né, saber por que ele quer aquele recurso, se vale a pena ou não vale esse tipo de investimento que ele quer fazer. Se vai ter retor- no ou não, se vai ter mercado para isso, ou não. Então a gente procura fazer uma boa conversa na cooperativa e, e em alguns casos, a gente vai na propriedade e conversa; ver se ele tem capacidade para isso. (DIR7)

Com base nos argumentos aqui apresentados, pode-se concluir que a definição de dinheiro proposta pelos mediadores raramente menciona sua função técnica, isto é, sua capacidade de ampliar o capital e os rendimentos dos agricultores. Sua intenção é fornecer um conceito que vincule a necessidade prática dos agricultores à rede de significados partilhados no circuito Cresol SC/ RS. Em outros termos, os mediadores fornecem o conteúdo que identifica e diferencia o Sistema Cresol das demais instituições financeiras, sejam elas sistemas cooperativos ou bancos convencionais. Essas conclusões, além de reforçarem a ideia de Zelizer sobre a relação entre mundos aparentemente hostis, mostram motivações políticas dos mediadores e seus esforços para combinar ganhos financeiros dos associados com 0 fortalecimento da organização em que atuam, beneficiando-se desses resultados.

Por fim, os dados evidenciam também que, durante as três fases de atualização do circuito Cresol SC/RS, alguns aspectos se mantêm. Entre eles, o aumento da utilização do dinheiro, passando do financiamento das sementes (primeira fase) até o seguro de vida (terceira fase). Nesse rol, estão também a ampliação das relações de confiança por meio de visitas às propriedades dos candidatos ao financiamento e a busca de informações sobre a idoneidade dos pretendentes na vizinhança e em festas comunitárias e as consultas a estabelecimen- 
tos de comércio. Em suma, durante as três elaborações do circuito mudam-se os símbolos compartilhados e as estratégias dos mediadores, mas as práticas de marcação do dinheiro e a expectativa de realização de "boas combinações" entre cultura e dinheiro se mantêm, especialmente se analisada a intensificação da aproximação entre mediadores e agricultores.

\section{Conclusão}

Os dados mostram que os "quadros de referência" propostos pelos mediadores foram fundamentais para a atualização do circuito Cresol na medida em que operaram "boas combinações" entre a dimensão da racionalidade econômica e o universo de valores dos agricultores para o fortalecimento da organização. $O$ processo de racionalização foi ressignifcado a partir de novos quadros de referência, com base em um complexo sistema de significados que mesclam elementos de ordem: 1) política (inclusão social, proximidade com a realidade do agricultor, linguagem acessível e orientação do crédito); 2) cultural (importância da família, cooperação e ajuda mútua); 3) econômica (juros mais baixos, acompanhamento técnico, financiamento da produção e do consumo). Além disso, na organização desse circuito, o dinheiro emergiu como principal meio de articulação entre a dimensão racional/instrumental e um sistema de valores, o qual identifica, compara e demarca as fronteiras das transações comerciais/econômicas.

Nesse ínterim, os mediadores operaram, nas diferentes fases do circuito, a substituição de valores relacionados ao comunitarismo e à rede de vizinhança por temas como autoestima, realização, afirmação social e reciprocidade. Portanto, não está em questão a mudança de orientação da ação econômica, mas sim a atualização dos quadros de referência para internalização e fortalecimento de novos valores, símbolos, e para consolidação dos laços sociais. O pano de fundo dessa "atualização" deve-se à capacidade dos mediadores de operar a ambivalência entre "fechamento" e "abertura" do circuito, isto é, fechá-lo do ponto de vista da organização do dinheiro (ampliação dos produtos e serviços disponibilizados aos associados, linguagem, símbolos, pautas políticas) e, ao mesmo tempo, manter a comunicação com o exterior (SFN, Universidades etc.).

Em suma, este estudo reconhece que o dinheiro provoca a abertura da unidade doméstica, mas é o sistema de valores que significa a utilização do dinheiro e regula sua circulação. Nesse sentido, os mediadores agem sob a ameaça de que o relaxamento da significação do dinheiro causa a abertura do circuito e sua descaracterização.

As conclusões indicam, portanto, três aspectos básicos: 1) a transição do tradicionalismo econômico para a orientação racional da gestão ocorreu por meio da internalização (cultural) de uma orientação baseada no cálculo e na utilização extensa do dinheiro, portanto o cálculo e o dinheiro operam essa transformação cultural; 2) isso não significa que os valores de mercado dissolveram a influência dos valores culturais na significação do dinheiro; 3) é nesse ambiente que os mediadores trabalham para a construção de Circuitos Econômicos para significação de dinheiro e consequente articulação entre as dimensões da racionalidade instrumental e o sistema de valores.

Entre as lacunas deste estudo, as quais per- 
USOS E SIGNIFICADOS DO DINHEIRO: UMA ANÁLISE DAS ESTRATÉGIAS DOS MEDIADORES PARA ATUALIZAÇÃO DE CIRCUITOS ECONÔMICOS

mitem agendas de pesquisa futuras, está a opção em não abordar o tema do conflito como tema central. De fato, o aporte teórico utilizado não aponta para análise das consequências políticas negativas que as relações monetárias proporcionam. No entanto, este estudo não teve a intenção de marginalizar esse debate, mas limitou-se a demonstrar como os mediadores constroem significados para marcação social do dinheiro. Dessa forma, acredita-se que este estudo oferece um ponto de partida para estudos sobre relações arruinadas por inadimplência, endividamento e quebra de contrato. Com isso, poder-se-ia ampliar a compreensão sobre a complexa relação entre o universo dos valores e o custo social das dessas transações econômicas.

\section{Referências}

Abramovay, R. (1992). Paradigmas do capitalismo agrário em questão. São Paulo: Hucitec.

Abramovay, R. (2004). Entre Deus e o diabo: mercado e interação humana nas ciências sociais. Tempo Social - Revista de Sociologia da USP (Vol. 16, n. 2). São Paulo.

Abramovay, R., \& Bittencourt, G. (2003). Inovações institucionais no financiamento da agricultura familiar: o Sistema Cresol. Revista Economia Ensaios. (Vol. 16, n. 1, pp. 179-207) Uberlândia.

Bauer, M. W., \& Gaskell, G. (2002). Pesqui- sa qualitativa com texto, imagem e som: um manual prático. Petrópolis: Vozes.

McAdam, D., \& McCarthy, J., \& Zald, M. (eds). (1999) Movimientos sociales: perspectivas comparadas. Madrid: Istmo.

Schneider, S. (2003). Teoria social, agricultura familiar e pluriatividade. Revista Brasileira de Ciências Sociais [online]. (Vol. 18, n. 51, pp. 99-122).

Snow, D., \& Benford, R. (1992). Master Frames and Cycles of Protest. in Morris, A. D. \& Mueller, C. M. Frontiers in Social Movement Theory. New Haven: Yale University Press.

Zald, M. (1999). Cultura, ideología y creación de marcos estratégicos. In McAdam, D., McCarthy, J. D., \& Zald, M. Movimientos sociales: perspectivas comparadas. Madrid, Istmo.

Zelizer, V. (2002) La construction des circuits de commerce: notes sur l'importance des circuits personnels et impersonnels. In JeanMichel Servet \& Isabelle Guérin. Exclusion et Liens Financiers. Rapport du Centre Walras, Economica, pp. 425-429.

Zelizer, V. (2005). La signification social de l'argent. Trad. Christian Cler. Paris: Seuil.

Zelizer, V. (2010). Circuits in economics life. In Economics Lives. New York: Princeton University Press. 